\title{
Efecto de la inclusión de probiótico, prebiótico y simbiótico en la dieta sobre los parámetros productivos del cuy (Cavia porcellus)
}

\author{
Effect of dietary probiotic, prebiotic and their combination on the productive perfor- \\ mance of guinea pigs (Cavia porcellus)
}

\author{
Cynthia Valdizán G. ${ }^{1}$, Fernando Carcelén C. ${ }^{1,4}$, Miguel Ara G. ${ }^{1}$, Sandra Bezada Q. ${ }^{1}$, \\ Ronald Jiménez A. ${ }^{1,2}$, Ana Asencios M. ${ }^{1}$, Jorge Guevara V. ${ }^{3}$
}

\section{Resumen}

\begin{abstract}
El presente estudio evaluó el efecto de la inclusión de probiótico, prebiótico y la combinación de ambos (simbiótico) en la dieta sobre los parámetros productivos del cuy (Cavia porcellus). Se seleccionaron 50 cuyes machos de 3 días de edad de una línea materna Prolífica-Lechera desarrollada en la Estación IVITA-El Mantaro (Perú) y fueron distribuidos aleatoriamente en cinco tratamientos consistentes en una dieta basal de forrajes (rye-grass y trébol rojo) complementada con afrechillo de trigo (T5), más probiótico (T1), prebiótico (T2), simbiótico (T3) y antibiótico promotor del crecimiento (APC) (T4). El probiótico fue un consorcio de seis especies bacterianas aisladas del intestino y heces de cuy; el prebiótico fue un mananoligosacárido comercial y el APC fue Zn-bacitracina. La respuesta a los tratamientos fue evaluada por 56 días en términos de ganancia de peso, consumo de alimento y conversión alimenticia. No se observaron respuestas significativas ni consistentes por efecto de los tratamientos. La falta de respuesta al APC y las buenas ganancias de peso obtenidas sugieren que, bajo las condiciones del estudio, el balance microbiano intestinal de los animales era apropiado.
\end{abstract}

Palabras clave: cuy; probiótico; prebiótico; simbiótico; El Mantaro

${ }^{1}$ Laboratorio de Bioquímica, Nutrición y Alimentación Animal, Facultad de Medicina Veterinaria, Universidad Nacional Mayor de San Marcos, Lima, Perú

${ }^{2}$ Estación Experimental El Mantaro, Centro de Investigaciones IVITA, Universidad Nacional Mayor de San Marcos, Junín, Perú

${ }^{3}$ Escuela Académico Profesional de Ingeniería Agroindustrial, Facultad de Química e Ingeniería Química, Universidad Nacional Mayor de San Marcos, Lima, Perú

${ }^{4}$ E-mail: nandodeme@gmail.com

Recibido: 12 de julio de 2019

Aceptado para publicación: 28 de febrero de 2018 
The present study evaluated the effect of the inclusion of probiotic, prebiotic and the combination of both (symbiotic) in the diet on the productive parameters of guinea pigs (Cavia porcellus). Fifty 3-day-old male guinea pigs were selected from a ProlificDairy maternal line developed in the IVITA-El Mantaro Research Station (Peru) and randomly distributed in five treatments consisting of a basal diet of forages (rye-grass and red clover). supplemented with wheat bran (T5), plus probiotic (T1), prebiotic (T2), symbiotic (T3) and antibiotic growth-promoter (AGP) (T4). The probiotic was a mixture of six bacterial species isolated from the intestine and guinea pig faeces; the prebiotic was a commercial mannanoligosaccharide and the APC was Zn-bacitracin. The response to treatments was evaluated for 56 days in terms of body weight gain, feed intake and feed conversion ratio. No significant or consistent responses were observed as effect of the treatments. The lack of response to AGP and the good body weight gains obtained suggested that, under the conditions of the study, the intestinal microbial balance of the animals was appropriate.

Key words: guinea pig; probiotic; prebiotic; symbiotic; El Mantaro

\section{INTRODUCCIÓN}

El incremento en la demanda de carne de cuy (Cavia porcellus) trae consigo la necesidad de una crianza intensiva con gran cantidad de ejemplares, con el consiguiente problema de la aparición de enfermedades. El uso indiscriminado de antibióticos en concentraciones arbitrarias, sea para el control de enfermedades o en dosis subterapéuticas como promotores de crecimiento, puede generar problemas de manejo sanitario como la dificultad y retraso en la identificación de los agentes etiológicos y la aparición de microorganismos antibiótico-resistentes $(\mathrm{Cal}-$ vo, 2004).

Los problemas asociados al uso indiscriminado de antibióticos en los animales incluyen la presencia de trazas de antibióticos en los productos y subproductos animales, la cual limita su comercialización para el consumo humano (Vallejos et al., 2015). Por otro lado, el retiro de los antibióticos de la terapéutica de los animales de engorde también supone riesgos para la salud humana, al consumir carne de animales enfermos no trata- dos, y para el ganadero por el descenso de los niveles productivos de los animales afectados (Santomá et al., 2006). Estos inconvenientes han motivado el desarrollo de alternativas para obtener productos con efectos similares a los antibióticos promotores de crecimiento, pero sin sus desventajas. Entre ellos se encuentran los ácidos orgánicos, extractos naturales, probióticos, prebióticos, simbióticos y adsorbentes de toxinas (Marzo et al., 2001).

Un probiótico es definido como un suplemento alimenticio microbiano vivo que beneficia al hospedador mejorando su balance microbiano intestinal (Tellez et al., 2006). Según Fuller (1989), los probióticos compiten con los microorganismos patógenos por la adhesión en los receptores del epitelio intestinal y por nutrientes, así como pueden producir sustancias antibacterianas y estimulantes de la inmunidad. Por otro lado, Gibson y Roberfroid (1995) definen los prebióticos como «sustancias o productos que no son absorbidos o hidrolizados durante su tránsito por el aparato digestivo, sirven de sustrato a las bacterias beneficiosas, estimulando su crecimiento y/o su actividad metabólica, al- 
teran la microbiota intestinal de manera favorable para el hospedador e inducen efectos beneficiosos no sólo en el medio intestinal, sino también sistémicos. Dentro de las sustancias prebióticas, los más utilizados en animales son los mananoligosacáridos (MOS) y los fructooligosacáridos (FOS) (Bazay et al., 2013). Tres de los principales mecanismos de acción de los MOS o derivados de paredes celulares de levaduras de $S$. cerevisiae incluyen la capacidad de adsorber bacterias enteropatógenas, de mejorar la salud gastrointestinal y, finalmente, la capacidad para modular el sistema inmunológico (Hooge, 2004).

La importancia de los probióticos en la alimentación de los animales de granja se basa en las propiedades que se le atribuyen para mejorar la eficiencia en la conversión alimenticia y como promotores de crecimiento (Rosmini et al., 2004; Pettigrew, 2000; Hooge, 2004), lo cual ha sido demostrado en corderos (Lerna et al., 2001), bovinos (SwinneyFloyd et al., 1999) y en lechones (Davis et al., 2008). Según Rosen (2005), la suplementación de MOS en la dieta de pollos parrilleros presenta resultados similares a los obtenidos con antibióticos promotores de crecimiento. En cerdos y aves la suplementación de las dietas con MOS ha mostrado beneficios en términos de mejora en los parámetros productivos y de la salud del animal (Pettigrew, 2000; Hooge, 2004).

De este modo, probióticos, prebióticos y simbióticos surgen como alternativas al uso indiscriminado de antibióticos en terapéutica o como promotores de crecimiento. Los simbióticos no dejan residuos indeseables en las carnes. Sin embargo, a pesar de sus efectos benéficos en otras especies (pollos, lechones, cerdos), no se tiene información sobre su uso en la alimentación del cuy, ni su efecto sobre los parámetros productivos. Por esta razón, el presente estudio tuvo como objetivo evaluar el efecto de la inclusión de probiótico, prebiótico y simbiótico en la dieta del cuy sobre los parámetros productivos

\section{Materiales y Métodos}

\section{Lugar de Estudio}

El estudio se realizó entre febrero y abril de 2015, estación de lluvias, en la Unidad de Cuyes de la Estación Experimental El Mantaro del Centro de Investigaciones IVITA, ubicada en el distrito de El Mantaro, provincia de Jauja, departamento de Junín (Perú), a una altitud de $3320 \mathrm{~m}$ sobre el nivel del mar.

\section{Arreglo Experimental}

Cincuenta cuyes hembras preñadas de la línea materna (Prolífica-Lechera) de los Cuyes Reproductores Geniales (RG), obtenida en el Centro de Investigación IVITA (Jiménez y Huamán, 2010) fueron aleatoriamente distribuidas, una semana antes de la fecha probable del parto, en cinco tratamientos (10 hembras por tratamiento): T1: Dieta base más probiótico; T2: Dieta base más prebiótico; T3: Dieta base más simbiótico; T4: Dieta base más antibiótico promotor del crecimiento (APC, control positivo); T5: Dieta base (control negativo).

Las hembras fueron alojadas individualmente en pozas de $1 \times 1.1 \times 0.7 \mathrm{~m}$, previamente desinfectadas, acondicionadas con cama de paja de cebada de $10 \mathrm{~cm}$ de espesor y equipadas con comederos y bebederos. La dieta base consistió en una mezcla forrajera complementada con afrechillo de trigo. La mezcla forrajera fue rye grass italiano (Lolium perenne) y trébol rojo (Trifolium pratense) en partes iguales, ofertada en una ración diaria de $6 \%$ (base seca) del peso corporal en forrajeras fijas de malla y alambre galvanizado. La composición proximal de la mezcla forrajera fue 24.1, 21.2, 2.4, 14.3, 9.0 y $53.2 \%$ de materia seca, proteína cruda, extracto etéreo, fibra cruda, cenizas y extracto no nitrogenado, respectivamente. El afrechillo de trigo fue suministrado en una ración diaria de $4 \%$ del peso corporal en recipientes de arcilla de 0.51 . El agua fue ofrecida ad libitum en bebederos de arcilla, reemplazándose el contenido cada día. 
Al tercer día de nacidas y por cuatro días consecutivos, las crías recibieron la suplementación pertinente a los tratamientos que fueron asignadas las madres. El destete se hizo en el día 16 con un peso promedio de 279 g. Se seleccionó al azar una cría macho por cada madre para formar grupos de 10 crías machos por tratamiento. Los machos se alojaron individualmente en 50 pozas experimentales de $0.6 \times 0.7 \times 0.4 \mathrm{~m}$ con piso de cemento y paredes de madera y malla. El acondicionamiento y la dieta base, incluyendo el racionamiento, fueron semejantes a los empleados con las madres.

El mismo día del destete se reinició la aplicación de los tratamientos por cuatro días consecutivos y en las mismas dosis aplicadas previamente. Esta suplementación se repitió a partir del día 42 del nacimiento por cinco días consecutivos. Este programa de aplicación persigue, primero, una siembra inicial de bacterias benéficas en el intestino del recién nacido para evitar la colonización de bacterias patógenas; segundo, una resiembra en el destete, momento que ocurren cambios en la dieta y de gran estrés en el animal, desplazando a las bacterias patógenas que pueden aprovechar estos cambios; y tercero, propiciar una mejor salud intestinal en el inicio del desarrollo y engorde del animal.

\section{Probiótico, Prebiótico, Simbiótico y APC}

El probiótico utilizado fue un consorcio de seis especies bacterianas aisladas de la mucosa del yeyuno e íleon y de heces de cuyes neonatos de 2-6 días de edad y adultos de 60 días de edad, cultivadas en medios enriquecidos y medios diferenciales (Porturas, 2011), a las cuales se les realizó una caracterización fenotípica y se les identificó mediante técnicas moleculares (Casti1lo, 2006). El producto es elaborado por Reinmark SRL y comercializado bajo el nombre de 'Biomodulador de Cuyes'. La composición del producto es de $30 \%(300 \mathrm{ml})$ del consorcio bacterial Enterococcus hirae 2.1 x $10^{10}$ bacterias $/ \mathrm{ml}$, Lactobacillus reuteri 3.3 x $10^{10}$ bacterias $/ \mathrm{ml}$, Lactobacillus frumenti
$3.1 \times 10^{10}$ bacterias $/ \mathrm{ml}$, Lactobacillus jhonsoni $2.2 \times 10^{10}$ bacterias $/ \mathrm{ml}$, Strepcoccus thoraltensis $2.3 \times 10^{10}$ bacterias $/ \mathrm{ml}$ y Bacillus pumillus $3.3 \times 10^{10}$ bacterias $/ \mathrm{ml}$ y $70 \%$ (700 ml) de un dilutor de $600 \mathrm{ml}$ de ácido láctico $25 \%$ y $100 \mathrm{ml}$ de agua deionizada estéril. Se usaron las dosis recomendadas por el fabricante, excepto que estas fueron administradas directamente, en vez de diluirse en el agua de bebida. En T1 y T3, la suspensión probiótica fue administrada vía oral ( $3 \mathrm{ml} /$ día) con una jeringa de $1 \mathrm{ml}$. En T2, T4 y $\mathrm{T} 5$ se repitió este procedimiento, pero con agua destilada.

El prebiótico empleado fue un MOS fosforilado comercializado bajo el nombre de Bio-Mos $^{\hat{a}}\left(\right.$ Alltech $\left.^{\hat{a}}\right)$, desarrollado a partir de las paredes celulares de la levadura Saccharomyces cerevisiae. Bio-Mos ${ }^{\hat{a}}$ es promocionado como un modificador biológico de la flora intestinal. El prebiótico fue administrado en T2 y $\mathrm{T} 3$ mezclado con el afrechillo de trigo en una proporción de $3 \mathrm{~kg}$ de Bio-Mos por $1000 \mathrm{~kg}$ de afrechillo. T3 (simbiótico), por lo tanto, consistió en la administración simultánea de probiótico y prebiótico en las mismas condiciones que en la aplicación individual en los tratamientos T1 y $\mathrm{T} 2$.

El APC utilizado en T4 fue el $\mathrm{Zn}$ Bacitracina (Promozinb ${ }^{a} 10 \%$, Lab. CUSA) administrado en mezcla con el afrechillo a una concentración de 300 ppm (3 kg de Promozimb ${ }^{a}$ por $1000 \mathrm{~kg}$ de afrechillo). Se utilizó una balanza Excell AWH3 con un nivel de precisión de $1 \mathrm{~g}$ para el pesaje de los alimentos y de los aditivos de las raciones.

\section{Variables de Respuesta}

Se evaluó la ganancia de peso vivo, el consumo de alimento y el índice de conversión alimenticia (ICA). La ganancia de peso vivo fue determinada por la diferencia entre el peso inicial (día 3 después del parto) y el peso final (día 59 después del parto) en gramos. Los pesos fueron registrados individualmente antes de suministrar el alimento. Para 
determinar el consumo se pesaron diariamente el forraje y el afrechillo ofrecidos, mientras que los residuos se pesaron semanalmente. El consumo, en términos de gramos de materia seca, se determinó mediante la suma de las diferencias semanales entre el alimento (forraje más afrechillo) ofrecido y el alimento (forraje más afrechillo) residual. El ICA fue calculado individualmente como los gramos de alimento necesarios para producir un gramo de peso vivo.

\section{Análisis de Datos}

El efecto de la administración de probiótico, prebiótico y simbiótico sobre la ganancia de peso vivo, consumo de alimento y conversión alimenticia fue analizado por medio de un análisis de varianza para un diseño experimental completamente al azar con cinco tratamientos y 10 repeticiones y el siguiente modelo aditivo lineal: $\mathrm{Y}_{\mathrm{ij}}=\mu+\tau_{\mathrm{i}}+\varepsilon_{\mathrm{ij}}$, donde $Y_{i j}$ es cualquier observación de la respuesta, $\mu$ es el efecto de la media, $\tau_{\mathrm{i}}$ es el efecto de los tratamientos y $\varepsilon_{\mathrm{ij}}$ es el efecto residual. Adicionalmente, se contrastaron las respuestas de los tratamientos mediante la prueba de rango múltiple de Duncan. Los cálculos estadísticos se ejecutaron con ayuda del programa R 3.4.3. (R Core Team, 2013). El nivel de significancia para las pruebas estadísticas fue de 0.05 .

\section{Resultados y Discusión}

No se encontraron diferencias significativas en términos de ganancia de peso y conversión alimenticia por efecto de la administración de probiótico, prebiótico, simbiótico o APC con respecto al grupo control (Cuadro 1). La ausencia de respuesta a probióticos y prebióticos también ha sido reportada en cerdos, donde Barros et al. (2008) usando $B$. subtilis $\left(1 \times 10^{10} \mathrm{UFC} / \mathrm{g}\right)$ como probiótico $\mathrm{y}$ un MOS como prebiótico no observaron diferencias significativas en la ganancia de peso vivo de lechones en fase de lactancia con respecto a la dieta control. No obstante, Wang et al. (2016) encontraron una mayor ganancia de peso vivo a los 41 días de edad en pollos tratados con probióticos (cepas de $B$. subtilis) o con probióticos más prebióticos (MOS y â-glucanos) en el alimento. En forma similar, Mookiah et al. (2004) utilizando probióticos (11 cepas de Lactobacillus) y prebióticos (isomalto-oligoacárido) obtuvieron mayores ganancias de peso en dos etapas del desarrollo de pollos Ross 308.

Se hace notar que el tratamiento con APC (control positivo) no haya incrementado la ganancia de peso de los cuyes sobre la dieta base. Son varios los mecanismos propuestos para explicar el efecto de los APC sobre el rendimiento animal; sin embargo, parece estar subyacente un efecto antibacterial en condiciones subclínicas (Feighner y Dashkevicz, 1987), efecto que supuestamente deberían emular los probióticos y prebióticos (Fuller, 1989) y cuya ausencia en este estudio sugiere que el balance microbiano en el tracto digestivo de los animales experimentales era apropiado. Lo anterior parece confirmarse por las ganancias de peso observadas, las cuales son superiores a las obtenidas en líneas de cuyes de engorde convencionales y comparables a las obtenidas en líneas seleccionadas por precocidad (Jiménez y Huamán, 2010).

La respuesta en términos de consumo de alimento tampoco fue consistente (Cuadro 1). La suplementación con probiótico o prebiótico, solos o combinados, no incrementó significativamente el consumo de alimento, mientras que la suplementación con APC redujo significativamente el consumo con respecto al control $(\mathrm{p}<0.05)$; sin embargo, es posible que esto sea un artefacto debido al cambio de olor o sabor del afrechillo de trigo por la adición del APC. Reducciones significativas en el consumo han sido observadas al incrementar la concentración de Znbacitracina en la ración de pollos de engorde (Reis et al., 2014). Barros et al. (2008) tampoco encontraron incrementos significativos en el consumo de alimento en lechones suplementados con probiótico, prebiótico y 
Cuadro 1. Ganancia de peso, consumo de alimento e índice de conversión alimenticia (ICA) en cuyes suplementados con probiótico, prebiótico, simbiótico (probiótico+ prebiótico) y antibiótico promotor del crecimiento (APC)

\begin{tabular}{cccc}
\hline Tratamiento & $\begin{array}{c}\text { Ganancia de peso } \\
(\mathrm{g})\end{array}$ & $\begin{array}{c}\text { Consumo de alimento } \\
(\mathrm{g})\end{array}$ & ICA \\
\hline Probiótico & $676^{\mathrm{a}}$ & $2816^{\mathrm{ab}}$ & $4.23^{\mathrm{a}}$ \\
Prebiótico & $708^{\mathrm{a}}$ & $2910^{\mathrm{ab}}$ & $4.20^{\mathrm{a}}$ \\
Simbiótico & $693^{\mathrm{a}}$ & $2842^{\mathrm{ab}}$ & $4.12^{\mathrm{a}}$ \\
APC & $697^{\mathrm{a}}$ & $2773^{\mathrm{b}}$ & $4.16^{\mathrm{a}}$ \\
Control & $684^{\mathrm{a}}$ & $3084^{\mathrm{a}}$ & $4.52^{\mathrm{a}}$ \\
\hline
\end{tabular}

Promedios con superíndices diferentes dentro de una misma columna son estadísticamente diferentes $(p<0.05)$

simbiótico en comparación con el grupo control. En forma similar, Abdel-Fattah y Fararh (2009), trabajando con una mezcla de Saccharomyces cerevisiae, Lactobacillus acidophilus, Streptococcus faecium y $B$. subtilis como probiótico, Bio-Mosâ como prebiótico, y con la mezcla de ambos (simbiótico) no observaron incrementos significativos en el consumo de alimento con respecto a control en pollos Sasso. En forma similar, Ashayerizadeh et al. (2009) trabajando con pollo Ross 308 con suplementación de probióticos (Lactobacillus casei, L. acidophilus, Bifidobacterium thermophilum y Enterococcus faecium) y un prebiótico comercial tampoco encontraron diferencias significativas en el consumo de alimento.

En contraste a los resultados en este estudio, Ashayerizadeh et al. (2009) observaron que tanto la adición del APC (flavomicina) o del simbiótico redujeron significativamente el ICA de 2.23 a $2.10 \mathrm{y}$ 2.08 , respectivamente. Asimismo, Fattah y Fararh (2009), encontraron que ICA mejor en aves suplementadas con simbiótico (2.19) y probiótico (2.23) en comparación con el grupo control (2.42), aunque sin especificar si estas diferencias fueron estadísticamente significativas.

\section{Conclusiones}

- No se obtuvo una respuesta significativa en el rendimiento productivo de cuyes por efecto de la inclusión en el alimento de un probiótico basado en una mezcla de cultivos bacterianos aislados del tracto digestivo y heces de cuy, ni de un prebiótico mananoligosacárido, en forma separada o combinados como un simbiótico.

- La falta de respuesta a estos aditivos sugiere que estos animales no se encontraban en un desbalance microbiano intestinal.

\section{Literatura Citada}

1. Abdel-Fattah F, Fararh K. 2009. Effect of dietary supplementation of probiotic, prebiotic and symbiotic on performance, carcass characteristics, blood picture and some biochemical parameters in broilers chickens. Benha Vet Med J 20: 9-23.

2. Ashayerizadeh A, Dabiri $N$, Ashayerizadeh $O$, Mirzadeh $K$, Roshanfekr H, Mamooee. 2009. Effect of dietary antibiotic, probiotic and 
prebiotic as growth promoters, on growth performance, carcass characteristics and hematological indices of broiler chickens. Pak J Biol Sci 12: 52-57.

3. Barros D, Camamori J, Corrêa V, de Abreu J, Fraga A, Mainardi F, Dutra V. 2008. Efeito da adição de probiótico e prebiótico sobre o ganho de peso, consumo de ração e ocorrência de diarréia em leitões na fase de aleitamento. Rev Bras Saúde Prod Anim 9: 469-479.

4. Bazay G, Carcelén F, Ara M, Jiménez J, González R, Quevedo W. 2013. Efecto de los manano-oligosacáridos sobre los parámetros productivos en cuyes (Cavia porcellus) durante la fase de engorde. Rev Inv Vet Perú 25: 198208. doi: $10.15381 /$ rivep.v25i2.8491

5. Calvo TMA. 2004. La resistencia bacteriana a los antibióticos. [Internet]. Disponible en: http://www.produccionanimal.com.ar/sanidad_intoxicaciones_metabolicos/infecciosas/ comun_varias_especies/37-resistencia_bacteriana_a_antibioticos.pdf

6. Castillo MSG 2006. Development of gut microbiota in the pig: modulation of bacterial communities by different feeding strategies. Tesis Doctoral. Barcelona, España: Univ. Autónoma de Barcelona. $233 \mathrm{p}$.

7. Davis M, Parrot T, Brown D, de Rodas $Z$, Jhonson B, Maxwell C, Rehberger T. 2008. Effect of a Bacillus based direct fed microbial feed supplement on growth performance and pen cleaning characteristics of growing finishing pigs. J Anim Sci 8: 1459-1467. doi: 10.2527/ jas.2007-0603

8. Feighner SD, Dashkevicz MP. 1987. Subtherapeutic levels of antibiotics in poultry feeds and their effects on weight gain, feed efficiency, and bacterial cholyltaurine hydrolase activity. Appl Environ Microb 53: 331-336.

9. Fuller R. 1989. Probiotics in man and animals. J Appl Bacteriol 66: 365-378. doi: 10.1111/j.1365-2672.1989.tb05105.x
10. Gibson GR, Roberfroid MB. 1995. Dietary modulation of the human colonic microbiota: introducing the concept of prebiotics. J Nutr 125: 1401-1412. doi: 10.1093/jn/125.6.1401

11. Hooge DM. 2004. Meta-analysis of broiler chicken pen trials evaluating dietary mannan oligosaccharide, 19932003. Int J Poult Sci 3: 163-174. doi: 10.3923/ijps.2004.163.174

12. Jiménez R, Huamán A. 2010. Cuyes genéticamente geniales: manual para el manejo de reproductores híbridos especializados en producción de carne. Lima: Univ. Nacional Mayor de San Marcos. 175 p.

13. Lerna M, Williams L, Rao DR. 2001. Reduction of fecal shedding of enterohemorrhagic Escherichia coli O157:H7 in lambs by feeding microbial feed supplement. Small Ruminant Res 39: 31-39. doi: 10.1016/S09214488(00)00168-1

14. Marzo I, Costa-Baltlori P, Urdí L. 2001. Nuevas estrategias en la alimentación del conejo: aditivos y alternativas al uso de antibióticos (Argent Export). [Internet]. Disponible en: http:// www.engormix.com/MA-cunicultura/ articulos/nuevas-estrategiasalimentacion-conejo-t371/141-p0.htm

15. Mookiah S, Sieo CC, Ramasamy K, Abdullah H, Ho YW. 2014. Effect of dietary prebiotics, probiotic, and symbiotics on performance, caecal bacterial populations and caecal fermentation concentration of broiler chickens. J Sci Food Agr 93: 341-348. doi: $10.1002 /$ jsfa.6365

16. Pettigrew J. 2000. Mannanoligosaccharides effects on performance reviewed. Feedstuffs 25: 12-14.

17. Porturas K. 2011. Aislamiento e identificación por técnicas moleculares de aislados bacterianos pertenecientes a géneros con potencial aplicación probiótica presentes en el intestino de cuyes ( $\mathrm{Ca}$ via porcellus). Tesis de Médico Veterinario. Lima, Perú: Univ. Nacional Mayor de San Marcos. 57 p. 
18. $R$ Core Team. 2013. R: a language and environment for statistical computing. $\mathrm{R}$ Foundation for Statistical Computing. Vienna, Austria. [Internet]. Disponible en: http://www.R-project.org/

19. Reis MP, Rodrigues PB, Cantarelli VS, Meneghetti C, García Jr AAP, de Lima RR, Fassani EJ, Naves LP. 2014. Níveis da bacitracina de zinco como melhorador do desempenho de frangos de corte. Ciênc Rural 44: 1093-1099. doi: 10.1590/S0103-84782014000600023

20. Rosen GD. 2005. Halo-analysis of effects of genetic, managemental, chronological and dietary variables on the efficacy of a pronutrient mannano-ligosaccharide in broilers. Brit Poultry Abstr 1: 27-29.

21. Rosmini MR, Sequeira GJ, Guerrero-Legarreta I, Martí LE, DallaSantina R, Frizzo L, Bonazza JC. 2004. Producción de probióticos para animales de abasto: importancia del uso de la microbiota intestinal indígena. Rev Mex Ing Quim 3: 181-191.

22. Santomá G, Pérez de Ayala P, Guitierrez del Alamo A. 2006. Producción de broilers sin antibióticos promotores de crecimiento actuales. En: LIII Symposium Cientificos de Avicultura. Barcelona, España.
23. Swinney-Floyd D, Gardner B, Owens F, Rebberger T, Parrott T. 1999. Effect of inoculation with either strain P-63 alone or in combination with Lactobacillus acidophilus LA53545 on performance of feedlot cattle. J Anim Sci 77(Suppl 1): 77.

24. Tellez G, Higgins SE, Donoghue AM, Hargis BM. 2006. Digestive physiology and the role of microorganisms. J Appl Poultry Res 15: 136-144. doi: 10.1093/ japr/15.1.136

25. Vallejos D, Carcelén F, Jiménez R, Perales $R$, Santillán G, Ara M, Quevedo W, Carzola F. 2015. Efecto de la suplementación con butirato de sodio en la dieta de cuyes (Cavia porcellus) de engorde sobre el desarrollo de las vellosidades intestinales y criptas de Lieberkühn. Rev Inv Vet Perú 26: $395-$ 403. doi: 10.15381/rivep.v26i3.11186

26. Wang X, Farnell_YZ, Peebles ED, Kiess AS, Wamsley KGS. 2016. Effects of prebiotics, probiotics, and their combination on growth performance, small intestine morphology, and resident Lactobacillus of male broilers. Poultry Sci 95: 1332-1340. doi: $10.3382 / \mathrm{ps} /$ pew030 